\title{
Predictive Value of Methicillin-Resistant Staphylococcus aureus (MRSA) Nasal Swab PCR Assay for MRSA Pneumonia
}

\author{
Benjamin Dangerfield, ${ }^{\text {a }}$ Andrew Chung, ${ }^{\text {b }}$ Brandon Webb, ${ }^{c}$ Maria Teresa Seville ${ }^{d}$ \\ Division of Internal Medicine, Maricopa Medical Center, Phoenix, Arizona, USA ${ }^{a}$; Division of Internal Medicine, Mayo Clinic in Arizona, Scottsdale, Arizona, USA ; Division of \\ Infectious Disease, University of Utah, Salt Lake City, Utah, USAc; Division of Infectious Diseases, Mayo Clinic in Arizona, Phoenix, Arizona, USA
}

Pneumonia due to methicillin-resistant Staphylococcus aureus (MRSA) is associated with poor outcomes and frequently merits empirical antibiotic consideration despite its relatively low incidence. Nasal colonization with MRSA is associated with clinical MRSA infection and can be reliably detected using the nasal swab PCR assay. In this study, we evaluated the performance of the nasal swab MRSA PCR in predicting MRSA pneumonia. A retrospective cohort study was performed in a tertiary care center from January 2009 to July 2011. All patients with confirmed pneumonia who had both a nasal swab MRSA PCR test and a bacterial culture within predefined time intervals were included in the study. These data were used to calculate sensitivity, specificity, positive predictive value, and negative predictive value for clinically confirmed MRSA pneumonia. Four hundred thirty-five patients met inclusion criteria. The majority of cases were classified as either health care-associated (HCAP) (54.7\%) or community-acquired (CAP) (34\%) pneumonia. MRSA nasal PCR was positive in $62(14.3 \%)$ cases. MRSA pneumonia was confirmed by culture in $25(5.7 \%)$ cases. The MRSA PCR assay demonstrated $88.0 \%$ sensitivity and $90.1 \%$ specificity, with a positive predictive value of $35.4 \%$ and a negative predictive value of $99.2 \%$. In patients with pneumonia, the MRSA PCR nasal swab has a poor positive predictive value but an excellent negative predictive value for MRSA pneumonia in populations with low MRSA pneumonia incidence. In cases of culture-negative pneumonia where initial empirical antibiotics include an MRSA-active agent, a negative MRSA PCR swab can be reasonably used to guide antibiotic de-escalation.

$\mathrm{M}$ ethicillin-resistant Staphylococcus aureus (MRSA) has emerged as an increasingly important pathogen in pulmonary infection, particularly in patients with significant health care exposure. Guidelines for health care-associated pneumonia (HCAP), hospital-acquired pneumonia (HAP), and ventilator-associated pneumonia (VAP) recommend empirical antibiotics targeting MRSA in at-risk patients (1). However, in many cases, cultures are negative and clinicians must determine in whom antibiotics can be safely de-escalated. S. aureus, including MRSA, colonizes the nares (2-6), and colonization has been shown to be a predictor of future clinical infection (7-12). MRSA nasal colonization can be accurately detected using the nasal swab PCR test $(13,14)$. It has been suggested, therefore, that the MRSA PCR nasal swab may be useful as a diagnostic test for patients with infections in whom MRSA is suspected. For this retrospective study, we describe the diagnostic characteristics of the nasal swab MRSA PCR test in predicting culture-confirmed MRSA pneumonia.

\section{MATERIALS AND METHODS}

The study was performed at a 244-bed academic tertiary care facility. Heart, kidney, liver, pancreas, and bone marrow transplantation are performed at our institution, but no obstetric or pediatric care is provided. Approval for the study was granted by the Mayo Clinic Institutional Review Board.

Cases were identified by querying the microbiology laboratory database for all patients who underwent nasal swab MRSA PCR testing from January 2009 to July 2011. During this period, routine admission MRSA surveillance was performed at our hospital for select groups only, including stem cell and solid organ transplant recipients and patients admitted with acute leukemia. No routine intensive care unit (ICU) surveillance program was in place during the study period. The majority of MRSA PCR assays reviewed for inclusion in our cohort were ordered for clinical diagnostic purposes in the intensive care unit and for internal medicine patients in the general and intermediate care areas. All PCR testing was performed using the Xpert MRSA (GeneXpert) system (Cepheid, Sunnyvale, CA).

For the same time period, all blood and respiratory cultures (sputum, induced sputum, or bronchoalveolar lavage) were also identified from laboratory records in an identical manner. Because the database was queried for all cultures during the study interval, this list included cultures positive for MRSA, cultures positive for organisms other than MRSA, and cultures with no bacterial growth. These two lists were then cross-referenced against each other to identify only patients who had undergone MRSA PCR testing and from whom a clinical culture specimen had been obtained. Cases were then manually reviewed and included only if they met study criteria for confirmed pneumonia. The case definition for pneumonia was based closely upon other studies in health care-associated pneumonia (15-18): radiographic evidence of infiltrate or cavitation and the presence of two or more of the following clinical signs or symptoms: (i) temperature less than $36.0^{\circ} \mathrm{C}$ or greater than $38.0^{\circ} \mathrm{C}$, (ii) respiratory rate greater than 20 , (iii) cough, (iv) hypoxia as evidenced by oxygen saturation less than $90 \%$ on room air, (v) increased sputum production, or (vi) a white blood cell count less than $4,000 / \mathrm{mm}^{3}$ or greater than $10,000 / \mathrm{mm}^{3}$.

Patients with confirmed pneumonia who had a nasal swab MRSA PCR test and from whom a culture specimen also was obtained were included in the study. Cases were excluded if another diagnosis was more likely than pneumonia and if the nasal MRSA PCR swab was not performed within 1 month prior to clinical culture for patients presenting from the outpatient setting or within 7 days prior to culture results in hospital-

Received 21 August 2013 Returned for modification 22 September 2013 Accepted 10 November 2013

Published ahead of print 25 November 2013

Address correspondence to Brandon Webb, brandonjohnwebb@gmail.com Copyright @ 2014, American Society for Microbiology. All Rights Reserved. doi:10.1128/AAC.01805-13 
TABLE 1 Patient characteristics

\begin{tabular}{|c|c|c|c|c|c|}
\hline \multirow[b]{2}{*}{ Characteristic } & \multicolumn{4}{|l|}{ Value for result } & \multirow[b]{2}{*}{ No. (\%) total } \\
\hline & $\begin{array}{l}\text { Positive PCR and } \\
\text { positive culture }\end{array}$ & $\begin{array}{l}\text { Positive PCR and } \\
\text { negative culture }\end{array}$ & $\begin{array}{l}\text { Negative PCR and } \\
\text { negative culture }\end{array}$ & $\begin{array}{l}\text { Negative PCR and } \\
\text { positive culture }\end{array}$ & \\
\hline No. of patients (all) & 22 & 40 & 370 & 3 & 435 \\
\hline \multicolumn{6}{|l|}{ Demographics } \\
\hline Avg age (yrs) & 74.2 & 72 & 69.1 & 79.3 & 69.7 \\
\hline No. male & 12 & 28 & 229 & 3 & $272(62.5)$ \\
\hline No. female & 10 & 12 & 141 & 0 & $163(37.5)$ \\
\hline \multicolumn{6}{|l|}{ No. with pneumonia type } \\
\hline CAP & 7 & 13 & 127 & 2 & $149(34.3)$ \\
\hline HCAP & 13 & 25 & 200 & 0 & $238(54.7)$ \\
\hline HAP & 2 & 2 & 43 & 1 & $48(11.0)$ \\
\hline \multicolumn{6}{|l|}{ Level of care } \\
\hline Medical/surgical unit & 13 & 25 & 214 & 2 & $254(58.4)$ \\
\hline Intermediate/ICU & 9 & 15 & 156 & 1 & $181(41.6)$ \\
\hline \multicolumn{6}{|l|}{ Antibiotic coverage } \\
\hline Empirical MRSA-active antibiotics given & 17 & 22 & 203 & 1 & $243(55.9)$ \\
\hline$\%$ of empirical MRSA coverage & 77.3 & 55.0 & 54.9 & 33.3 & \\
\hline
\end{tabular}

acquired cases. These cutoffs were chosen based upon studies indicating that colonization status in outpatients does not fluctuate rapidly in the absence of significant MRSA exposure $(19,20)$ and studies by Byrnes et al. (10) and Sarikonda et al. (12) suggesting that colonization status for inpatients can change within as few as 7 days from initial testing. The majority $(>80 \%)$ of culture specimens were obtained within $48 \mathrm{~h}$ of the MRSA swab.

Data abstracted from the electronic medical record included age, gender, type of pneumonia according to the American Thoracic Society/Infectious Diseases Society of America (ATS/IDSA) guidelines (CAP, HCAP, or HAP $[1,21]$ ), level of medical care (general medical/ surgical ward versus intermediate or intensive care unit), and use of empirical antibiotics directed against MRSA. Empirical antibiotics were defined as antibiotics administered within $8 \mathrm{~h}$ of admission for new admissions or the initial empirical regimen administered when HAP or VAP was suspected. The majority of MRSA PCR swabs were collected at the time of diagnosis of pneumonia, at or near the time of clinical culture collection and antibiotic administration. However, time stamp data from the electronic medical record was not accurate enough to determine whether the swab was collected prior to administration of anti-MRSA antibiotics.

The sensitivity, specificity, positive predictive value (PPV), and negative predictive value (NPV) of the MRSA nasal swab for detecting cultureproven MRSA pneumonia were calculated. Ninety-five percent confidence intervals were calculated according to the efficient-score method, corrected for continuity (22). Calculations were performed using a Webbased statistical software package (VassarStats [www.vassarstats.net]; accessed 14 June 2012).

\section{RESULTS}

During the study period, 2,740 patients had nasal swab MRSA PCR testing. Of the patients with nasal swabs, 696 had at least one blood or respiratory bacterial culture performed. Two hundred sixty-one patients were excluded because the duration of time between the MRSA nasal swab and pneumonia exceeded predefined limits $(n=87)$ or because another diagnosis was more likely than pneumonia $(n=174)$.

Four hundred thirty-five patients were included in the final analysis (Table 1). Average patient age was 69.7 years, and $62.5 \%$ were male. Sixty-two of 435 (14.3\%) MRSA nasal swabs were positive. For 25 of 435 patients, cultures were positive for MRSA (23 sputum and 2 blood samples), resulting in a prevalence of MRSA infection of $5.7 \%$ in our cohort. Most cases were classified as HCAP (54.7\%), with CAP and HAP comprising 34.3\% and $11.0 \%$ respectively. There were only 3 patients who met criteria for ventilator-associated pneumonia (VAP). Because of the limited number of VAP cases, these cases were included in HAP for analysis. Fifty-eight percent of patients were treated on the medical floor, and $41.6 \%$ were treated in the intermediate care or intensive care unit.

The nasal swab MRSA PCR test demonstrated the following diagnostic performance characteristics for detecting cultureproven MRSA: sensitivity, $88.0 \%$; specificity, $90.1 \%$; positive predictive value (PPV), 35.4\%; and negative predictive value (NPV), 99.2\%. The NPV of the MRSA nasal swab for MRSA HCAP was $100.0 \%$, for that for CAP was $98.4 \%$, and that for HAP was $97.7 \%$.

Slightly more than half (55.9\%) of all patients received empirical MRSA-active antibiotics, and $72.0 \%$ of the patients with culture-positive MRSA pneumonia received empirical therapy targeting MRSA. There was no statistical difference in the 30-day mortality ( 0 deaths versus 3 deaths) or the duration of hospitalization (4.7 and 6.9 days) between those treated with empirical MRSA antibiotics and those that were not $(P=0.40$ and 0.32 , respectively). Complete results are in Tables 1 to 4 .

\section{DISCUSSION}

When implicated as a primary pathogen in lower respiratory tract infection, MRSA is associated with significant morbidity and mortality $(23,24)$. This is particularly true when appropriate antibiotic therapy targeting MRSA is not included in an initial empirical regimen. However, determining which patients warrant antiMRSA coverage, and once that is initiated, when it is safe to narrow the antibiotic spectrum in the absence of positive cultures represents a clinical dilemma. 
TABLE 2 MRSA swab PCR results

\begin{tabular}{|c|c|c|c|}
\hline \multirow[b]{2}{*}{ MRSA swab PCR result } & \multicolumn{2}{|c|}{$\begin{array}{l}\text { No. }(\%) \text { of cases with culture } \\
\text { result }^{a}\end{array}$} & \multirow[b]{2}{*}{ Total swabs } \\
\hline & $\begin{array}{l}\text { Positive for } \\
\text { MRSA }\end{array}$ & $\begin{array}{l}\text { Negative for } \\
\text { MRSA }\end{array}$ & \\
\hline Positive swab & $22^{a}$ & $40^{b}$ & $62(14.3)$ \\
\hline Negative swab & $3^{c}$ & $370^{d}$ & $373(85.7)$ \\
\hline Total cultures & $25(5.7)$ & $410(94.3)$ & 435 \\
\hline \multicolumn{4}{|c|}{$\begin{array}{l}\text { a Specimens collected: sputum, } 18 \text { cases; blood, } 1 \text { case; bronchoalveolar lavage (BAL), } 2 \\
\text { cases; pleural plus BAL, } 1 \text { case. } \\
{ }^{b} \text { Specimens collected: sputum, } 1 \text { case; blood, } 25 \text { cases; blood plus sputum, } 9 \text { cases; } \\
\text { blood plus BAL, } 4 \text { cases; blood plus pleural, } 1 \text { case. } \\
{ }^{c} \text { A sputum sample was collected for each of the } 3 \text { cases. } \\
{ }^{d} \text { Specimens collected: } 17 \text { sputum, } 17 \text { cases; blood, } 180 \text { cases; BAL, } 2 \text { cases; blood plus } \\
\text { sputum, } 112 \text { cases; blood plus BAL, } 30 \text { cases; blood plus pleural, } 12 \text { cases; sputum plus } \\
\text { BAL, } 5 \text { cases; sputum plus pleural, } 1 \text { case; blood plus sputum plus BAL, } 5 \text { cases; blood } \\
\text { plus sputum plus pleural, } 5 \text { cases; blood plus BAL plus pleural, } 1 \text { case. }\end{array}$} \\
\hline
\end{tabular}

One barrier to accurate prediction is that the incidence of MRSA pneumonia appears to vary significantly with individual patient risk factors and local epidemiological patterns. In one large cohort from 162 hospitals in the United States, $8.9 \%$ of all culture-positive cases of CAP, $26.5 \%$ for HCAP, and $22.9 \%$ for HAP were attributable to MRSA (25), and similar rates have been reported from other large centers (17). Other studies, however, suggest much lower rates, with reported prevalences of $<0.6$ to $0.9 \%$ for $\operatorname{CAP}(16,26-29)$ and $2 \%$ to $3.5 \%$ for $\operatorname{HCAP}(16,26,29)$. In our cohort, the overall prevalence of MRSA pneumonia was $5.7 \%$, including a $6.0 \%$ rate among cases of CAP $(9 / 149), 5.5 \%$ for HCAP (13/238), and 6.3\% for HAP (3/48).

Nasal colonization with MRSA has been well established as a risk for subsequent clinical MRSA infection (2, 9, 30-34). In 2004, the National Nosocomial Infections Surveillance System reported a rate of MRSA colonization of $1.5 \%$ (7). This rate is higher among patients admitted to the hospital (3.4\%) (2), those admitted to the ICU (21.9\%) (12), and health care workers (4 to $15 \%)(35,36)$. The prevalence of nasal MRSA colonization in our hospital is 5 to $7 \%$. In our cohort of pneumonia patients, however, the overall rate of nasal colonization was $14.3 \%$ (62/435). Most studies have suggested that the duration of colonization appears to be about 1 year $(19,20)$, although some patients remain colonized for much longer periods (37). Those colonized by MRSA have been found to have a significantly increased risk of MRSA infection in the immediate hospitalization and the year following $(2,9,30-34,38)$. In patients with colonization lasting more than 1 year, the rate of subsequent clinical infection has been estimated at 23\% (38).

Although multiple studies have attempted to determine the utility of the MRSA nasal swab for predicting MRSA infection,

TABLE 3 Statistical analysis

\begin{tabular}{lll}
\hline Test characteristic & Result & $95 \%$ confidence interval \\
\hline Sensitivity (\%) & 88.0 & $67.6-96.9$ \\
Specificity (\%) & 90.1 & $86.6-92.8$ \\
Positive predictive value (\%) & 35.4 & $24.0-48.7$ \\
Negative predictive value (\%) & 99.2 & $97.4-99.8$ \\
Positive likelihood ratio & 8.9 & $6.4-12.3$ \\
Negative likelihood ratio & 0.1 & $0.05-0.39$ \\
\hline
\end{tabular}

TABLE 4 Analysis by pneumonia type

\begin{tabular}{lllll}
\hline & \multicolumn{3}{l}{ Test efficacy } \\
\cline { 2 - 5 } & $\begin{array}{l}\text { Sensitivity } \\
(\%)\end{array}$ & $\begin{array}{l}\text { Specificity } \\
(\%)\end{array}$ & $\begin{array}{l}\text { Positive } \\
\text { predictive } \\
\text { value }(\%)\end{array}$ & $\begin{array}{l}\text { Negative } \\
\text { predictive } \\
\text { value }(\%)\end{array}$ \\
Pneumonia type(s) $\left(n^{a}\right)$ & $(98.0$ & 90.1 & 35.4 & 99.2 \\
All (435) & 77.8 & 90.7 & 35.0 & 98.4 \\
CAP $(149)$ & 100.0 & 88.9 & 34.2 & 100.0 \\
HCAP (238) & 66.7 & 95.6 & 50.0 & 97.7 \\
HAP (48) & & & & \\
\hline
\end{tabular}

${ }^{a} n$, total no. of patients.

significant heterogeneity exists with regard to the use of PCR versus chromogenic culture medium, body site sampled for colonization, and timing $(8,11,12,39,40)$. The two largest of these studies, a retrospective review by Robicsek et al. (11) and a prospective analysis by Harris et al. (8), both suggest that the nasal MRSA PCR (GeneOhm; Becton, Dickinson and Company) demonstrates a modest PPV but an NPV greater than $98 \%$ for MRSA infection at any body site. In subgroup data analysis of 426 patients with respiratory specimens, Robicsek et al. reported an NPV of $98 \%$; the prevalence of MRSA infection in this group was $5.6 \%$. In contrast, in a prospective study of 1,083 ICU patients using the same PCR-based assay, Sarikonda et al. found that surveillance MRSA nasal swab PCR screening on admission had a sensitivity of $24.2 \%$, specificity of $78.5 \%$, PPV of $17.7 \%$, and NPV of $84.4 \%$ for MRSA lower respiratory infection $(12,41)$.

In our cohort, the overall NPV of the MRSA nasal swab PCR for MRSA infection was excellent at $99.2 \%$, while the PPV was $35.5 \%$ when the test was used in the diagnosis of pneumonia. Similar results were observed when the test was applied to each of the three categories of pneumonia. The diagnostic performance was best in the HCAP group, where an NPV of $100 \%$ was calculated. These results are consistent with those of larger studies, which suggest that, as with MRSA infection at other body sites, determination of MRSA colonization is useful in the evaluation of suspected respiratory infection due to MRSA. The modest differences in performance of the MRSA PCR in our cohort compared to that in the Sarikonda study are likely related to underlying factors impacting the prevalence of MRSA in the two populations. Both the prevalence of MRSA colonization (24.4\% versus $14.3 \%$ ) and infection $(21.9 \%$ versus $5.7 \%)$ were much higher in the Sarikonda group, contributing to a lower NPV. In addition, only $43 \%$ of patients in our group were treated in the ICU or intermediate care unit, of which less than $2 \%$ had ventilator-associated pneumonia (VAP).

Our findings have several important implications for antimicrobial stewardship. First, our experience suggests that clinicians remain unsure when to initiate empirical MRSA coverage. In our cohort, $56 \%$ of patients received initial empirical antibiotics with activity against MRSA, including only $72 \%$ of patients who were ultimately diagnosed with MRSA pneumonia. Current ATS/IDSA guidelines for CAP and HCAP recommend therapy targeting MRSA if risk factors, such as cavitating pneumonia, end-stage renal disease, injection drug abuse, prior influenza, and prior antibiotic therapy, are present or if local prevalence is high $(1,21)$. The HCAP category itself was originally proposed as a method for identifying multidrug-resistant pathogens, including MRSA, in 
patients with pneumonia. However, the positive predictive value of the HCAP criteria for MRSA pneumonia in highly MRSA-prevalent (14\%) populations is only $26.5 \%$ (25) and is as low as $3.6 \%$ in low-prevalence settings (29).

Additional risk factors for MRSA pneumonia, including fever of $>39.0^{\circ} \mathrm{C}$, hemoptysis, leukopenia, MRSA colonization, frequent skin/soft tissue infection, chronic obstructive pulmonary disease (COPD), tobacco use, recent hospitalization, HIV infection, and liver disease, have been identified in other studies (42, 43). However, in isolation each of these factors lacks sensitivity and specificity, and none have been studied in combination. Recently Shorr et al. derived the following clinical prediction score for MRSA pneumonia from a relatively high-prevalence (14\%) cohort: two points for recent hospitalization and one point each for an age of $<30$ or $>79$, prior intravenous (i.v.) antibiotic exposure, dementia, cerebrovascular disease, status as a diabetic female, or recent stay in a long-term residence facility (44). At scores of 0 or 1 , the model identified patients with a $<10 \%$ risk of MRSA $(\mathrm{PPV}=19.6 \%$; NPV 90.1\%), while the prevalence of MRSA pneumonia increased to $>30 \%$ with scores of $\geq 6$. Interestingly, even in our relatively low-prevalence cohort, the positive predictive value of the MRSA PCR nasal swab was superior to that of any of the screening methods described above. While this test cannot be advocated as a diagnostic modality based on these results, further research may be warranted to evaluate the possible additive benefit of combining clinical prediction models and the MRSA PCR assay.

In clinical practice, empirical anti-MRSA agents are increasingly included in the initial empirical regimen, and in culturenegative cases, safe and appropriate de-escalation poses an additional challenge. Recently, Boyce et al. described the successful implementation of an MRSA screening strategy to assist in de-escalation (45). For 91 patients admitted with HCAP, in-hospital mortality was no different following discontinuation of MRSA-active therapy if nasal and throat swabs cultured on chromogenic MRSA agar were negative and if the modified clinical pulmonary infection score (CPIS) was $\leq 6$. Given the robust NPV of the MRSA PCR test in our cohort, which included a large subset of patients meeting HCAP criteria, our results suggest that MRSA PCR testing can be an important tool to guide antibiotic de-escalation following empirical antiMRSA therapy. In areas with high baseline MRSA prevalence or in individual patients for whom pretest probability of infection is high, coupling the MRSA PCR nasal swab to a clinical prediction rule, such as a Shorr MRSA score of $\leq 1$ or CPIS of $\leq 3$, may augment the negative predictive value. This remains to be evaluated.

Limitations of this study include its retrospective design, which precluded more rigorous control of such variables as timing of MRSA swab collection and standardization of culture work-up. It is conceivable that in some cases, administration of MRSA-active agents prior to collection for MRSA PCR could have contributed to false-negative testing or conversely obscured clinical cultures leading to false-positive results. Many $(70.2 \%)$ of the respiratory cultures were performed with sputum specimens (Table 2), which differentiate upper respiratory tract colonization from lower-tract pathogens less accurately than do cultures collected via bronchoscopy. In addition, only swabs of the nares were obtained, which may have limited the diagnostic yield of our assay. Some studies have demonstrated that swabbing both the nares and the throat may increase the sensitivity of MRSA screening (45). Indeed, this may offer a possible explanation for the 3 cases in our study in which nasal swab testing was negative but sputum cultures were positive (false-negative results). Last, the overall prevalence of MRSA pneumonia in this study was average by national standards at $5.7 \%$. Our results may not be generalizable to centers with a substantially higher prevalence of MRSA or individual patients with risk factors that convey a high pretest probability of MRSA infection.

Conclusion. The results of this retrospective analysis suggest that in patients with pneumonia, the nasal swab MRSA PCR test has a mediocre positive predictive value but an excellent negative predictive value for MRSA in centers with a moderate background prevalence of MRSA pneumonia. A potentially important clinical implication of these results is that for patients treated empirically with antibiotics with MRSA activity, a nasal swab negative for MRSA by PCR can be reasonably used to guide antibiotic deescalation provided that the pretest probability of MRSA pneumonia is not extremely high. A prospective trial is needed in order to confirm these findings.

\section{ACKNOWLEDGMENTS}

We report no external funding source for this study.

We have no conflicts of interest to report.

\section{REFERENCES}

1. American Thoracic Society. 2005. Guidelines for the management of adults with hospital-acquired, ventilator-associated, and healthcareassociated pneumonia. Am. J. Respir. Crit. Care Med. 171:388-416. http: //dx.doi.org/10.1164/rccm.200405-644ST.

2. Davis KA, Stewart JJ, Crouch HK, Florez CE, Hospenthal DR. 2004. Methicillin-resistant Staphylococcus aureus (MRSA) nares colonization at hospital admission and its effect on subsequent MRSA infection. Clin. Infect. Dis. 39:776-782. http://dx.doi.org/10.1086/422997.

3. Hidron AI, Kourbatova EV, Halvosa JS, Terrell BJ, McDougal LK, Tenover FC, Blumberg HM, King MD. 2005. Risk factors for colonization with methicillin-resistant Staphylococcus aureus (MRSA) in patients admitted to an urban hospital: emergence of community-associated MRSA nasal carriage. Clin. Infect. Dis. 41:159-166. http://dx.doi.org/10 $.1086 / 430910$.

4. Kenner J, O'Connor T, Piantanida N, Fishbain J, Eberly B, Viscount H, Uyehara C, Hospenthal D. 2003. Rates of carriage of methicillin-resistant and methicillin-susceptible Staphylococcus aureus in an outpatient population. Infect. Control Hosp. Epidemiol. 24:439-444. http://dx.doi.org /10.1086/502229.

5. Kuehnert MJ, Kruszon-Moran D, Hill HA, McQuillan G, McAllister SK, Fosheim G, McDougal LK, Chaitram J, Jensen B, Fridkin SK, Killgore G, Tenover FC. 2006. Prevalence of Staphylococcus aureus nasal colonization in the United States, 2001-2002. J. Infect. Dis. 193:172-179. http://dx.doi.org/10.1086/499632.

6. Reboli AC, John JF, Jr, Platt CG, Cantey JR. 1990. Methicillin-resistant Staphylococcus aureus outbreak at a Veterans' Affairs Medical Center: importance of carriage of the organism by hospital personnel. Infect. Control Hosp. Epidemiol. 11:291-296. http://dx.doi.org/10.1086/646174.

7. National Nosocomial Infections Surveillance System. 2004. National Nosocomial Infections Surveillance (NNIS) System Report, data summary from January 1992 through June 2004, issued October 2004. Am. J. Infect. Control 32:470-485. http://dx.doi.org/10.1016/j.ajic.2004.10.001.

8. Harris AD, Furuno JP, Roghmann MC, Johnson JK, Conway LJ, Venezia RA, Standiford HC, Schweizer ML, Hebden JN, Moore AC, Perencevich EN. 2010. Targeted surveillance of methicillin-resistant Staphylococcus aureus and its potential use to guide empiric antibiotic therapy. Antimicrob. Agents Chemother. 54:3143-3148. http://dx.doi.org/10.1128 /AAC.01590-09.

9. Safdar N, Bradley EA. 2008. The risk of infection after nasal colonization with Staphylococcus aureus. Am. J. Med. 121:310-315. http://dx.doi.org /10.1016/j.amjmed.2007.07.034. 
10. Byrnes MC, Adegboyega T, Riggle A, Chipman J, Beilman G, Reicks P, Boeser K, Irwin E. 2010. Nasal swabs collected routinely to screen for colonization by methicillin-resistant Staphylococcus aureus in intensive care units are a sensitive screening test for the organism in clinical cultures. Surg. Infect. (Larchmt.) 11:511-515. http://dx.doi.org/10.1089/sur.2010 .033 .

11. Robicsek A, Suseno M, Beaumont JL, Thomson RB, Jr, Peterson LR 2008. Prediction of methicillin-resistant Staphylococcus aureus involvement in disease sites by concomitant nasal sampling. J. Clin. Microbiol. 46:588-592. http://dx.doi.org/10.1128/JCM.01746-07.

12. Sarikonda KV, Micek ST, Doherty JA, Reichley RM, Warren D, Kollef MH. 2010. Methicillin-resistant Staphylococcus aureus nasal colonization is a poor predictor of intensive care unit-acquired methicillin-resistant Staphylococcus aureus infections requiring antibiotic treatment. Crit. Care Med. 38:1991-1995. http://dx .doi.org/10.1097/CCM.0b013e3181eeda3f.

13. Kelley PG, Grabsch EA, Howden BP, Gao W, Grayson ML. 2009. Comparison of the Xpert methicillin-resistant Staphylococcus aureus (MRSA) assay, BD GeneOhm MRSA assay, and culture for detection of nasal and cutaneous groin colonization by MRSA. J. Clin. Microbiol. 47: 3769-3772. http://dx.doi.org/10.1128/JCM.00303-09.

14. Andersen BM, Tollefsen T, Seljordslia B, Hochlin K, Syversen G, Jonassen TO, Rasch M, Sandvik L. 2010. Rapid MRSA test in exposed persons: costs and savings in hospitals. J. Infect. 60:293-299. http://dx.doi .org/10.1016/j.jinf.2010.01.008.

15. Carratala J, Mykietiuk A, Fernandez-Sabe N, Suarez C, Dorca J, Verdaguer R, Manresa F, Gudiol F. 2007. Health care-associated pneumonia requiring hospital admission: epidemiology, antibiotic therapy, and clinical outcomes. Arch. Intern. Med. 167:1393-1399. http://dx.doi.org/10 $.1001 /$ archinte.167.13.1393.

16. Chalmers JD, Taylor JK, Singanayagam A, Fleming GB, Akram AR, Mandal P, Choudhury G, Hill AT. 2011. Epidemiology, antibiotic therapy, and clinical outcomes in health care-associated pneumonia: a UK cohort study. Clin. Infect. Dis. 53:107-113. http://dx.doi.org/10.1093/cid /cir274.

17. Micek ST, Kollef KE, Reichley RM, Roubinian N, Kollef MH. 2007. Health care-associated pneumonia and community-acquired pneumonia: a single-center experience. Antimicrob. Agents Chemother. 51:35683573. http://dx.doi.org/10.1128/AAC.00851-07.

18. Shorr AF, Zilberberg MD, Micek ST, Kollef MH. 2008. Prediction of infection due to antibiotic-resistant bacteria by select risk factors for health care-associated pneumonia. Arch. Intern. Med. 168:2205-2210. http://dx.doi.org/10.1001/archinte.168.20.2205.

19. Lucet JC, Paoletti X, Demontpion C, Degrave M, Vanjak D, Vincent C, Andremont A, Jarlier V, Mentre F, Nicolas-Chanoine MH. 2009. Carriage of methicillin-resistant Staphylococcus aureus in home care settings: prevalence, duration, and transmission to household members. Arch. Intern. Med. 169:13721378. http://dx.doi.org/10.1001/archinternmed.2009.217.

20. Sanford MD, Widmer AF, Bale MJ, Jones RN, Wenzel RP. 1994. Efficient detection and long-term persistence of the carriage of methicillin-resistant Staphylococcus aureus. Clin. Infect. Dis. 19:1123-1128. http: //dx.doi.org/10.1093/clinids/19.6.1123.

21. Mandell LA, Wunderink RG, Anzueto A, Bartlett JG, Campbell GD, Dean NC, Dowell SF, File TM, Jr, Musher DM, Niederman MS, Torres A, Whitney CG. 2007. Infectious Diseases Society of America/American Thoracic Society consensus guidelines on the management of community-acquired pneumonia in adults. Clin. Infect. Dis. 44(Suppl 2):S27-S72. http://dx.doi.org/10.1086/511159.

22. Newcombe RG. 1998. Two-sided confidence intervals for the single proportion: comparison of seven methods. Stat. Med. 17:857-872. http://dx.doi.org/10.1002 /(SICI) 1097-0258(19980430)17:8<857::AID-SIM777>3.0.CO;2-E.

23. Jeffres MN, Isakow W, Doherty JA, McKinnon PS, Ritchie DJ, Micek ST, Kollef MH. 2006. Predictors of mortality for methicillin-resistant Staphylococcus aureus health-care-associated pneumonia: specific evaluation of vancomycin pharmacokinetic indices. Chest 130:947-955. http: //dx.doi.org/10.1378/chest.130.4.947.

24. Taneja C, Haque N, Oster G, Shorr AF, Zilber S, Kyan PO, Reyes KC, Moore C, Spalding J, Kothari S, Zervos M. 2010. Clinical and economic outcomes in patients with community-acquired Staphylococcus aureus pneumonia. J. Hosp. Med. 5:528-534. http://dx.doi.org/10.1002/jhm.704.

25. Kollef MH, Shorr A, Tabak YP, Gupta V, Liu LZ, Johannes RS. 2005. Epidemiology and outcomes of health-care-associated pneumonia: results from a large US database of culture-positive pneumonia. Chest 128:3854 3862. http://dx.doi.org/10.1378/chest.128.6.3854.
26. Grenier C, Pepin J, Nault V, Howson J, Fournier X, Poirier MS, Cabana J, Craig C, Beaudoin M, Valiquette L. 2011. Impact of guidelineconsistent therapy on outcome of patients with healthcare-associated and community-acquired pneumonia. J. Antimicrob. Chemother. 66:16171624. http://dx.doi.org/10.1093/jac/dkr176.

27. Lobo LJ, Reed KD, Wunderink RG. 2010. Expanded clinical presentation of community-acquired methicillin-resistant Staphylococcus aureus pneumonia. Chest 138:130-136. http://dx.doi.org/10.1378/chest.09-1562.

28. Moran GJ, Krishnadasan A, Gorwitz RJ, Fosheim GE, Albrecht V, Limbago B, Talan DA. 2012. Prevalence of methicillin-resistant staphylococcus aureus as an etiology of community-acquired pneumonia. Clin. Infect. Dis. 54:1126-1133. http://dx.doi.org/10.1093/cid/cis022.

29. Shindo Y, Sato S, Maruyama E, Ohashi T, Ogawa M, Hashimoto N, Imaizumi K, Sato T, Hasegawa Y. 2009. Health-care-associated pneumonia among hospitalized patients in a Japanese community hospital. Chest 135:633-640. http://dx.doi.org/10.1378/chest.08-1357.

30. Garrouste-Orgeas M, Timsit JF, Kallel H, Ben Ali A, Dumay MF, Paoli B, Misset B, Carlet J. 2001. Colonization with methicillin-resistant Staphylococcus aureus in ICU patients: morbidity, mortality, and glycopeptide use. Infect. Control Hosp. Epidemiol. 22:687-692. http://dx.doi.org/10 $.1086 / 501846$

31. Honda H, Krauss MJ, Coopersmith CM, Kollef MH, Richmond AM, Fraser VJ, Warren DK. 2010. Staphylococcus aureus nasal colonization and subsequent infection in intensive care unit patients: does methicillin resistance matter? Infect. Control Hosp. Epidemiol. 31:584-591. http://dx .doi.org/10.1086/652530.

32. Huang SS, Hinrichsen VL, Datta R, Spurchise L, Miroshnik I, Nelson K, Platt R. 2011. Methicillin-resistant Staphylococcus aureus infection and hospitalization in high-risk patients in the year following detection. PLoS One 6:e24340. http://dx.doi.org/10.1371/journal.pone.0024340.

33. Keene A, Vavagiakis P, Lee MH, Finnerty K, Nicolls D, Cespedes C, Quagliarello B, Chiasson MA, Chong D, Lowy FD. 2005. Staphylococcus aureus colonization and the risk of infection in critically ill patients. Infect. Control Hosp. Epidemiol. 26:622-628. http://dx.doi.org/10.1086/502591.

34. Patel M, Weinheimer JD, Waites KB, Baddley JW. 2008. Active surveillance to determine the impact of methicillin-resistant Staphylococcus aureus colonization on patients in intensive care units of a Veterans Affairs Medical Center. Infect. Control Hosp. Epidemiol. 29:503-509. http://dx .doi.org/10.1086/588161.

35. Bisaga A, Paquette K, Sabatini L, Lovell EO. 2008. A prevalence study of methicillin-resistant Staphylococcus aureus colonization in emergency department health care workers. Ann. Emerg. Med. 52:525-528. http://dx .doi.org/10.1016/j.annemergmed.2008.03.019.

36. Suffoletto BP, Cannon EH, Ilkhanipour K, Yealy DM. 2008. Prevalence of Staphylococcus aureus nasal colonization in emergency department personnel. Ann. Emerg. Med. 52:529-533. http://dx.doi.org/10.1016/j .annemergmed.2008.03.020.

37. Scanvic A, Denic L, Gaillon S, Giry P, Andremont A, Lucet JC. 2001. Duration of colonization by methicillin-resistant Staphylococcus aureus after hospital discharge and risk factors for prolonged carriage. Clin. Infect. Dis. 32:1393-1398. http://dx.doi.org/10.1086/320151.

38. Datta R, Huang SS. 2008. Risk of infection and death due to methicillinresistant Staphylococcus aureus in long-term carriers. Clin. Infect. Dis. 47:176-181. http://dx.doi.org/10.1086/589241.

39. Chaberny IF, Schwab F, Ziesing S, Suerbaum S, Gastmeier P. 2008 Impact of routine surgical ward and intensive care unit admission surveillance cultures on hospital-wide nosocomial methicillin-resistant Staphylococcus aureus infections in a university hospital: an interrupted timeseries analysis. J. Antimicrob. Chemother. 62:1422-1429. http://dx.doi .org/10.1093/jac/dkn373.

40. Harbarth S, Fankhauser C, Schrenzel J, Christenson J, Gervaz P, Bandiera-Clerc C, Renzi G, Vernaz N, Sax H, Pittet D. 2008. Universal screening for methicillin-resistant Staphylococcus aureus at hospital admission and nosocomial infection in surgical patients. JAMA 299:11491157. http://dx.doi.org/10.1001/jama.299.10.1149.

41. Hombach M, Pfyffer GE, Roos M, Lucke K. 2010. Detection of methicillin-resistant Staphylococcus aureus (MRSA) in specimens from various body sites: performance characteristics of the BD GeneOhm MRSA assay, the Xpert MRSA assay, and broth-enriched culture in an area with a low prevalence of MRSA infections. J. Clin. Microbiol. 48:3882-3887. http: //dx.doi.org/10.1128/JCM.00670-10.

42. Dean N. 2010. Methicillin-resistant Staphylococcus aureus in community-acquired and health care-associated pneumonia: incidence, diagnosis, 
and treatment options. Hosp. Pract. 38:7-15. http://dx.doi.org/10.3810 /hp.2010.02.274.

43. Wooten DA, Winston LG. 2013. Risk factors for methicillin-resistant Staphylococcus aureus in patients with community-onset and hospitalonset pneumonia. Respir. Med. 107:1266-1270. http://dx.doi.org/10 .1016/j.rmed.2013.05.006.

44. Shorr AF, Myers DE, Huang DB, Nathanson BH, Emons MF, Kollef MH. 2013. A risk score for identifying methicillin-resistant Staphylococ- cus aureus in patients presenting to the hospital with pneumonia. BMC Infect. Dis. 13:268. http://dx.doi.org/10.1186/1471-2334-13-268.

45. Boyce JM, Pop OF, Abreu-Lanfranco O, Hung WY, Fisher A, Karjoo A, Thompson B, Protopapas Z. 2013. A trial of discontinuation of empiric vancomycin therapy in patients with suspected methicillinresistant Staphylococcus aureus health care-associated pneumonia. Antimicrob. Agents Chemother. 57:1163-1168. http://dx.doi.org/10 .1128/AAC.01965-12. 